\title{
Complications of Obesity in Cesarized Parturients in the Teaching Centers of Cotonou
}

\author{
Annelie Kerekou Hode ${ }^{1 *}$, Eugène Zoumenou ${ }^{2}$, Benjamin Hounkpatin ${ }^{3}$, Serge Mewanou ${ }^{4}$, \\ Blaise Tchaou ${ }^{5}$, Martin Chobli 6
}

\begin{abstract}
${ }^{1}$ Service of Endocrinology, Hospital and University National Center Hubert Koutoukou Maga of Cotonou, Cotonou, Benin ${ }^{2}$ Service of Anesthesia and Reanimation, Hospital Mother and Child of Cotonou, Cotonou, Benin ${ }^{3}$ Service of Gynecology and Obstetrics, Hospital Mother and Child of Cotonou, Cotonou, Benin ${ }^{4}$ Service of Anesthesia and Reanimation, Hospital and University National Center Hubert Koutoukou Maga of Cotonou, Cotonou, Benin

${ }^{5}$ Department of Anesthesia and Reanimation, Hospital and University of Parakou, Parakou, Benin ${ }^{6}$ Emergency Department of Hospital and University National Center Hubert Koutoukou Maga of Cotonou, Cotonou, Benin Email: ^kerekouannelie@yahoo.fr, ezoumenou@yahoo.fr, bhounkpatin@yahoo.fr, mewanous@yahoo.fr, tchblaise@yahoo.fr, mchobli@yahoo.fr
\end{abstract}

How to cite this paper: Hode, A.K., Zoumenou, E., Hounkpatin, B., Mewanou, S., Tchaou, B. and Chobli, M. (2018) Complications of Obesity in Cesarized Parturients in the Teaching Centers of Cotonou. Open Journal of Endocrine and Metabolic Diseases, 8, 137-144.

https://doi.org/10.4236/ojemd.2018.86014

Received: May 5, 2018

Accepted: June 25, 2018

Published: June 28, 2018

Copyright (c) 2018 by authors and Scientific Research Publishing Inc. This work is licensed under the Creative Commons Attribution International License (CC BY 4.0).

http://creativecommons.org/licenses/by/4.0/

\begin{abstract}
This survey had the objective to determine the frequency of the obesity at the parturient, to value the impact of the obesity on the childbirth by Caesarean and the complications postoperative immediate in the teaching hospitals of Cotonou. Patients and Method: We did a prospective, comparative and analytic survey from January 13 to April 13, 2012. Eight hundred ninety-one consecutive parturients having had a Caesarean were included. We studied the anesthetic techniques, the techniques of control of the aerial ways, the number of necessary tests for the tracheal intubation, the complications and aftercare of the first 48 hours. A comparison has been made according to the BMI. The obesity has been defined by a BMI $\geq 30 \mathrm{~kg} / \mathrm{m}^{2}$. The parturient has been classified in two groups: Non-obese: $\mathrm{BMI} \leq 30 \mathrm{~kg} / \mathrm{m}^{2}$, obese: $\mathrm{BMI} \geq 30$. Results: There were 703 (78.90\%) Caesareans in emergency and 188 (21.09\%) programmed Caesareans. The obesity which has been recovered at 286 parturient is $32.10 \%$. The obese parturient also required more frequently several lumbar punctures $(\mathrm{p}<0.001)$ at the time of the spinal anesthesia and more of conversion of the spinal anesthesia into a general anesthesia $(p=0.008)$. The postoperative complications: laryngeal pain, back pain and suppuration of the wound were more frequent at the obese parturient. Conclusion: Many changes led by pregnancy are added to those of the obesity to drive to functional changes, a reduction of the physiological reserve and finally to an in-
\end{abstract}


creased anesthetic and obstetric risk. The obesity is frequent at the parturient in Benin. The post-operative complications are more frequent after the Caesarean at the obese parturient.

\section{Keywords}

Obesity, Caesarean, Anesthesia, Complication, Benin

\section{Introduction}

According to a WHO's report, more than a third of the women and a quarter of the men in Africa are in overweight, and these proportions should increase to $41 \%$ and $30 \%$ respectively during the next ten years. The recent tendencies in the urbanization of the developing countries and the internationalization of the food market contribute to changing the behavior of people and their style of life. These changes of lifestyle, bound to the nutrition, transition of the traditional to the modern habits, have driven to the emergence of the overweight and the obesity [1] [2]. A hospitable survey led to Cotonou returns a prevalence of overweight of $35.3 \%$ and the one of the obesity to $27.3 \%$ with a feminine predominance: $16.9 \%$ at the men vs $36 \%$ at the women [3]. The morbidity townships of the obesity at the women are the complications of pregnancy, the dystocia, and the childbirths by Caesarian procedure [4] [5] [6].

This survey had the objective to determine the frequency of the obesity at the parturient, to value the impact of the obesity on the childbirth by Caesarean and the complications postoperative immediate in the teaching hospitals of Cotonou.

\section{Patient and Method}

Our survey took place in the service of anesthesia resuscitation, the operative blocks, to the intensive care, the delivery rooms, the services of hospitalization, the neonatology service of two academic motherhoods of Benin,. We did a prospective, comparative and analytic survey of January 13 to April 13, 2012. After the favorable opinion of the local ethics committee and the consent of the parturient. We collected the data by a standardized questionnaire. The information we collected included age, height, weight, BMI, Co-morbidities, gestational and parity, anesthetic technique, complications, indications for Caesarean section, cesarean section modalities, the satisfaction of the parturient. All parturients who had a Caesarian procedure during this study period were included either Eight hundred ninety-one parturients. We studied the anesthetic techniques, the techniques of control of the aerial ways, the number of necessary tests for the tracheal intubation, the complications and aftercare of the first 48 hours. A comparison has been made according to the BMI. The obesity has been defined by a $B M I \geq 30 \mathrm{~kg} / \mathrm{m}^{2}$. The parturient has been classified in two groups: Non obese: $\mathrm{BMI} \leq 30 \mathrm{~kg} / \mathrm{m}^{2}$, obese: $\mathrm{BMI} \geq 30$. The obese have been classified in 
4 groups: moderate obesity: BMI between 30 and $35 \mathrm{~kg} / \mathrm{m}^{2}$; stern obesity: BMI splices 35 and $40 \mathrm{~kg} / \mathrm{m}^{2}$; morbid obesity: BMI $\geq 40 \mathrm{~kg} / \mathrm{m}^{2}$; terrific obese: $\mathrm{BMI} \geq$ $50 \mathrm{~kg} / \mathrm{m}^{2}$ [7]. The primary criteria of judgment were the prevalence of the obesity, the choice of the anesthetic technique and the difficulties bound to the anesthetic technique. The secondary judgment criteria were the intervening of a complication perioperative.

The collected data have been seized with the help of the software SPSS 18 and have been analyzed with the software Epi-Info 3.3.2. The qualitative variables have been described while using the percentages and their interval of confidence. The quantitative variables have been described while using the average and the gap marks. The comparisons of frequency have been made with the help of the test of Chi Square and the comparisons of average with the test of Student. A p been worth lower or equal to 0.05 has been considered like statistically meaningful.

\section{Results}

There were $703(78.90 \%)$ Caesareans in emergency and 188 (21.09\%) programmed Caesareans. The obesity has been recovered at 286 parturient is $32.10 \%$. Among the 286 obese, $57.69 \%$ (165) had an obesity moderates; $28.32 \%$ (81) had a stern obesity, $13 \%$ (37) had a morbid obesity and $1.04 \%$ (3) were terrific obese. The obese parturient had a more elevated middle gravidity to 3.03 and a more elevated middle parity to 1.56 . The high BP, OSAS and the burrs were the co-morbidities the more frequently recovered at the obese parturient (Table 1).

Table 1. Distribution according to BMI and characteristics of women in labor.

\begin{tabular}{|c|c|c|c|c|c|}
\hline \multirow[b]{2}{*}{ Effective total } & \multicolumn{2}{|c|}{$\mathrm{BMI}<30$} & \multicolumn{2}{|c|}{$\mathrm{BMI} \geq 30$} & \multirow[t]{2}{*}{$\mathrm{p}$} \\
\hline & 605 & $(67.90 \%)$ & 286 & $(32.10 \%)$ & \\
\hline Age $<18$ ans & 11 & $1.82 \%$ & 1 & $0.35 \%$ & 0.063 \\
\hline $18-45$ ans & 593 & $98.02 \%$ & 283 & $98.95 \%$ & 0.237 \\
\hline$>45$ ans & 1 & $0.17 \%$ & 2 & $0.7 \%$ & 0.243 \\
\hline Mean Gravidity & $2.66 \pm 1.588$ & & $3.03 \pm 1.803$ & & $<0.001$ \\
\hline Mean Parity & $1.28 \pm 1.422$ & & $1.56 \pm 1.653$ & & $<0.001$ \\
\hline \multicolumn{6}{|l|}{ Co-morbidity } \\
\hline Arterial hypertension & 108 & $17.85 \%$ & 76 & $26.57 \%$ & 0.002 \\
\hline Diabetes & 8 & $1.32 \%$ & 2 & $0.70 \%$ & 0.328 \\
\hline Asthma & 19 & $3.14 \%$ & 14 & $4.90 \%$ & 0.135 \\
\hline Snoring & 106 & $17.52 \%$ & 104 & $36.36 \%$ & $<0.001$ \\
\hline OSAS & 18 & 2.98 & 44 & $15.38 \%$ & $<0.001$ \\
\hline Cardiopathy & 6 & $0.99 \%$ & 7 & $2.45 \%$ & 0.085 \\
\hline Other & 81 & 13.39 & 30 & $10.49 \%$ & 0.132 \\
\hline
\end{tabular}

OSAS: Obstructive sleep apnea syndrome. 
There were 703 (78.90\%) Caesareans in emergency and 188 (21.09\%) programmed Caesareans. The Caesarean was programmed more frequently at the obese parturient ( $\mathrm{p}=0.003$ ) (Table 2). Didn't have a meaningful difference in the indications according to the BMI. The indications of the Caesarean were the uterine scars, the acute fetal distress and the pre-eclampsia. There was not a difference between the indications in the two groups.

The spinal anesthesia and the general anesthesia was practiced with the same frequency at the obese parturient as non-obese (Table 3). The obese parturient had a score of Mallampati more frequently therefore superior to 2 were more susceptible to present some difficulties the intubation. These parturient required several laryngoscopies more frequently before the intubation (Table 3 ). The obese parturient also required more frequently several lumbar punctures $(p<$ 0.001 ) at the time of the spinal anesthesia and more of conversion of the spinal anesthesia into an anesthesia general $\mathrm{p}=0.008$ (Table 3 ).

The postoperative complications: laryngeal pain, back pain and suppuration of the wound were more frequent at the obese parturient (Table 4). All other complications (stern hypotension, failure of intubation, laryngospasm, hypoxia, inhalation, cardiac stop, belated wakening, respiratory distress, postoperative headache, postoperative nauseas and vomiting, cough, neck pain, thrills) didn't depend of the BMI. The only case of death by cardiac arrest noted in postoperative was due to anemia bound to sickle cell disease otherwise there were no post-operative death.

Table 2. Distribution of women in labor according to BMI, type of Caesarian and indication.

\begin{tabular}{|c|c|c|c|c|c|}
\hline & \multicolumn{2}{|c|}{$\mathrm{BMI}<30 \mathrm{~kg} / \mathrm{m}^{2}$} & \multicolumn{2}{|c|}{$\mathrm{BMI} \geq 30 \mathrm{~kg} / \mathrm{m}^{2}$} & $\mathrm{p}$ \\
\hline Emergency & 494 & $81.65 \%$ & 209 & $73.08 \%$ & 0.003 \\
\hline Scheduled & 111 & $18.35 \%$ & 77 & $26.92 \%$ & 0.003 \\
\hline \multicolumn{6}{|l|}{ Indications } \\
\hline Dystocia & 168 & $27.77 \%$ & 76 & $26.57 \%$ & 0.386 \\
\hline Preeclampsia & 91 & $15.04 \%$ & 56 & $19.58 \%$ & 0.055 \\
\hline Eclamptic crisis & 48 & $7.93 \%$ & 16 & $5.59 \%$ & 0.13 \\
\hline Uterine scar & 151 & $24.96 \%$ & 78 & $27.27 \%$ & 0.255 \\
\hline PP & 31 & $5.12 \%$ & 20 & $6.99 \%$ & 0.281 \\
\hline Placenta hematoma & 18 & $2.98 \%$ & 6 & $2.18 \%$ & 0.304 \\
\hline UR & 35 & $5.79 \%$ & 11 & $3.85 \%$ & 0.144 \\
\hline Acute fetal distress & 171 & $28.26 \%$ & 68 & $23.78 \%$ & 0.091 \\
\hline Prophylactic & 50 & $8.26 \%$ & 26 & $9.09 \%$ & 0.384 \\
\hline Fetal macrosomia & 4 & $0.66 \%$ & 6 & $2.10 \%$ & 0.064 \\
\hline Other & 14 & $2.31 \%$ & 6 & $2.10 \%$ & 0.445 \\
\hline
\end{tabular}


Table 3. Distribution of women in labor according to BMI, type of anesthesia and complications.

\begin{tabular}{|c|c|c|c|c|c|}
\hline \multirow[b]{2}{*}{ Spinal anesthésia } & \multicolumn{2}{|c|}{$\mathrm{BMI}<30$} & \multicolumn{2}{|c|}{$\mathrm{BMI} \geq 30$} & \multirow{2}{*}{$\begin{array}{c}\mathrm{P} \\
0.334\end{array}$} \\
\hline & 486 & $80.33 \%$ & 234 & $81.82 \%$ & \\
\hline Multiple lumbarpunction & 290 & $47.93 \%$ & 192 & $67.13 \%$ & $<0.001$ \\
\hline Failure to lumbarpunction & 0 & $0.00 \%$ & 3 & $1.05 \%$ & 0.033 \\
\hline Severe low blood pressure & 118 & $19.50 \%$ & 57 & $19.93 \%$ & 0.474 \\
\hline Reconversion in general anesthésia & 13 & $2.15 \%$ & 16 & $5.59 \%$ & 0.008 \\
\hline General anesthesia & 119 & $19.67 \%$ & 52 & $18.18 \%$ & 0.334 \\
\hline Mallampati 1 & 311 & $51.40 \%$ & 61 & $21.30 \%$ & $<0.001$ \\
\hline Mallampati 2 & 183 & $30.20 \%$ & & $36.4 \%$ & 0.041 \\
\hline Mallampati 3 & 78 & $12.90 \%$ & & $28.00 \%$ & $<0.001$ \\
\hline Mallampati 4 & 33 & $5.50 \%$ & & $14.30 \%$ & $<0.001$ \\
\hline Multiple laryngoscopy & 43 & $7.11 \%$ & 36 & $12.59 \%$ & 0.006 \\
\hline Failure to intubation & 6 & $0.99 \%$ & 4 & $1.40 \%$ & 0.407 \\
\hline Laryngospasm & 1 & $0.17 \%$ & 0 & $0.00 \%$ & 0.313 \\
\hline Hypoxia & 77 & $12.73 \%$ & 41 & $14.34 \%$ & 0.287 \\
\hline Bronchial inhalation & 0 & $0.00 \%$ & 1 & $0.35 \%$ & 0.321 \\
\hline Cardiac arrest & 1 & $0.17 \%$ & 0 & $0.00 \%$ & 0.679 \\
\hline Pulmonary distress & 2 & $0.33 \%$ & 2 & $0.70 \%$ & 0.385 \\
\hline Late awakening & 5 & $0.83 \%$ & 5 & $1.75 \%$ & 0.385 \\
\hline
\end{tabular}

Table 4. Distribution of women in labor according to BMI and immediate post operatives complications.

\begin{tabular}{cccccc}
\hline & \multicolumn{2}{c}{ BMI $<30$} & \multicolumn{2}{c}{ BMI $\geq 30$} & P \\
\hline Post operatives headaches & 66 & $10.91 \%$ & 38 & $13.29 \%$ & 0.178 \\
Post operatives nausea and vomiting & 88 & $14.55 \%$ & 52 & $18.18 \%$ & 0.099 \\
Laryngeal pain & $\mathbf{2 8}$ & $\mathbf{4 . 6 3 \%}$ & $\mathbf{2 2}$ & $\mathbf{7 . 6 9 \%}$ & $\mathbf{0 . 0 4 7}$ \\
Cough & 6 & $0.99 \%$ & 1 & $0.35 \%$ & 0.286 \\
Neck pain & 6 & $0.99 \%$ & 4 & $1.40 \%$ & 0.407 \\
Chills & 24 & $3.97 \%$ & 13 & $4.55 \%$ & 0.404 \\
Lumbar pain & 11 & $\mathbf{1 . 8 2 \%}$ & $\mathbf{1 2}$ & $\mathbf{4 . 2 0 \%}$ & $\mathbf{0 . 0 3 4}$ \\
Suppurating wound & $\mathbf{0}$ & $\mathbf{0 . 0 0 \%}$ & $\mathbf{6}$ & $\mathbf{2 . 1 0 \%}$ & $\mathbf{0 . 0 0 1}$ \\
\hline
\end{tabular}

\section{Discussion}

This survey permitted to determine the prevalence of the obesity at the parturient that benefitted from the Caesarean in the academic hospitals of Cotonou, and to determine the impact of the obesity on the complications of the Caesarean. 
The prevalence of the obesity at these parturient was of $32.10 \%$. It was superior to the $10.73 \%$ of the general population in the Benin [8]. Although the WHO defined the obesity for a $\mathrm{BMI} \geq 30 \mathrm{Kg} / \mathrm{m}^{2}$; at the parturient it is necessary to take account of the supplementary weight contained in the uterus, of the Sodium retention and the supplementary greasy mass of due to the pregnancy. The obesity would be defined then at the parturient for a BMI $\geq 35 \mathrm{Kg} / \mathrm{m}^{2}$ [9]. The prevalence of the obesity at the parturient would be then of $24.80 \%$. It remained superior to the $14.52 \%$ recovered in the urban population by Gary et al. [7].

Our survey was only carried on the parturient having benefitted a Caesarean and no on the set of the parturient. We could not define the frequency of Caesarean among the obese parturient in relation to the non-obese parturient. The obesity at the parturient is associated to affections as: the arterial hypertension, the diabetes, the asthma, the pre-eclampsia and the OSAS [10]. In our survey this association was meaningful for the arterial hypertension, the nocturnal burrs and the OSAS. At the obese pregnant women, the OSAS is even more frequent and the episodes of arterial desaturation in oxygen that can occur during the syndrome of apnea of the sleep are a threat for the mother and the fetus [11].

Many changes led by pregnancy are added to those of the obesity to drive to functional changes, a reduction of the physiological reserve and finally to an increased anesthetic and obstetric risk [12]. The œedema of the aerial ways, the greasy deposits to the level of the soft cloths of the aerial ways, the short neck and the volume of the breasts contribute to the difficulty of the intubation. The obese parturient had a score of Mallampati more 3 and 4 in relation to the non-obese parturient. The difficulty of intubation has been observed at $12.59 \%$ of the parturient obese vs $7.11 \%$ at the non-obese parturient. The impact of the failures of the intubation is the order of $1 / 280$ at the parturient against $1 / 2230$ in the general population of the patients operated [13] [14] [15]. The failure of the intubation was observed at $1.40 \%$ of the parturient obese vs $0.99 \%$ of the non-obese parturient. The spinal anesthesia is recommended therefore especially at the obese parturient [16]. The spinal anesthesia was preferentially the technique the more used $(80.80 \%)$ for the Caesarean in our survey as well at the obese parturient that non obese. This technique associated the bupivacaine to the fentanyl and/or to morphine. The difficulty of the lumbar puncture was more frequent $(67.13 \%$ vs $47.93 \%$ of multiple puncture) at the obese parturient. This tendency has been returned by Vricella et al. [10].

The laryngeal pains were more frequent at the obese that the non-obese. It explains itself comfortably by the number more raised of laryngoscopy. In the same way, there was more back pain at the obese that the non-obese. This result is only a consequence of the multiple lumbar punctures. The suppuration of the operative wound was observed solely at the obese parturient. What joins the observations of Lebuffe et al. [17]. The thickness of the adipose tissue plays an important role in the intervening of this complication. The adipose tissue is hypoperfused what makes hypoxic the sub-cutaneous tissue at the obese and delay the skinning. 


\section{Conclusion}

Our survey reveals that the obesity's frequency increased depending on the number of pregnancy and childbirth. Obesity increased the risk of occurred hypertension, apnea sleep syndrome and snoring. It increased the difficulties of lumbar puncture at a spinal anesthesia with an important risk of using the general anesthesia. Immediate complications due to obesity were postoperative wound suppurations and long-term back pain.

\section{Conflicts of Interest}

The authors declare no conflicts of interest regarding the publication of this paper.

\section{References}

[1] Godfrey, R. and Julien, M. (2005) Urbanisation and Health. Clinical Medicine, 5, 137-141. https://doi.org/10.7861/clinmedicine.5-2-137

[2] Popkin, B.M. (2002) An Overview on the Nutrition Transition and Its Health Implications: The Bellagio Meeting. Public Health Nutrition, 5, 93-103.

[3] Kerekou Hode, A., Bocovo, M., Amoussou-Guenou, D. and Djrolo, F. (2013) Survey on the Prevalence of Overweight and Obesity at the Outpatients Medicine Service of $\mathrm{Cnhu} / \mathrm{hkm}$ in Cotonou. Les annales de I Université de Parakou, 3, 21-23.

[4] Kabiru, W. (2004) RBD Obstetric Outcomes Associated with Increase in BMI Category during Pregnancy. American Journal of Obstetrics and Gynecology, 191, 928-932. https://doi.org/10.1016/j.ajog.2004.06.051

[5] Saravanakumar, K., Rao, S.G. and Cooper, G.M. (2006) Obesity and Obstetric Anesthesia: Review Article. Anaesthesia, 61, 36-48. https://doi.org/10.1111/j.1365-2044.2005.04433.x

[6] Robinson, H.E. (2005) Maternal Outcomes in Pregnancy Complicated by Obesity. Obstetrics \& Gynecology, 106, 1357-1364. https://doi.org/10.1097/01.AOG.0000188387.88032.41

[7] Organization, W.H. (2000) Obesity: Preventing and Managing the Global Epidemic. World Health Organization, Geneva.

[8] Gbary, A.R., Kpozehouen, A., Houehanou, Y.C., et al. (2014) Prevalence and Risk Factors of Overweight and Obesity: Findings from a Cross-Sectional Community-Based Survey in Benin. Global Epidemic Obesity, 2, 3. https://doi.org/10.7243/2052-5966-2-3

[9] Bamgbade, O., Khalaf, W., Ajai, O., Sharma, R., Chidambaram, V. and Madhavan, G. (2009) Obstetric Anaesthesia Outcome in Obese and Non-Obese Parturients Undergoing Caesarean Delivery: An Observational Study. International Journal of Obstetric Anesthesia, 18, 221-225. https://doi.org/10.1016/j.ijoa.2008.07.013

[10] Vricella, L.K., Louis, J.M., Mercer, B.M. and Bolden, N. (2010) Anesthesia Complications during Scheduled Cesarean Delivery for Morbidly Obese Women. American Journal of Obstetrics and Gynecology, 203, 276.e1-e5. https://doi.org/10.1016/j.ajog.2010.06.022

[11] Mace, H., Paech, M. and McDonnell, N. (2011) Obesity and Obstetric Anaesthesia. Anaesthesia and Intensive Care, 39, 559.

[12] Devroe, S. and Van de Velde, M. (2012) Anesthésie de la parturiente obèse. Le Pra- 
ticien en anesthésie reanimation, 16, 153-160.

https://doi.org/10.1016/j.pratan.2012.04.006

[13] Hawthorne, L., Wilson, R., Lyons, G. and Dresner, M. (1996) Failed Intubation Revisited: 17-Yr Experience in a Teaching Maternity Unit. British Journal of Anaesthesia, 76, 680-684. https://doi.org/10.1093/bja/76.5.680

[14] Barnardo, P. and Jenkins, J. (2000) Failed Tracheal Intubation in Obstetrics: A 6-Year Review in a UK Region. Anaesthesia, 55, 690-694. https://doi.org/10.1046/j.1365-2044.2000.01536.x

[15] Samsoon, G. and Young, J. (1987) Difficult Tracheal Intubation: A Retrospective Study. Anaesthesia, 42, 487-490. https://doi.org/10.1111/j.1365-2044.1987.tb04039.x

[16] Loubert, C. and Fernando, R. (2011) Cesarean Delivery in the Obese Parturient: Anesthetic Considerations. Women's Health, 7, 163-179. https://doi.org/10.2217/WHE.10.77

[17] Lebuffe, G., Andrieu, G., Wierre, F., et al. (2010) Anesthésie-réanimation chez l'obèse. Journal de Chirurgie Viscérale, 147, S10-S19.

https://doi.org/10.1016/j.jchirv.2010.08.015 